\title{
STATIC-DYNAMIC MODEL FOR ENDPOINT CONTROL USED IN SMEDEREVO'S BOF SHOP
}

\author{
T. D. Bradarić ${ }^{*}$ Z. M. Slović ${ }^{2}$, G. J. Stepanoski ${ }^{3}$, S. Kosanović ${ }^{4}$ \\ ${ }^{1}$ KOTEH Engineering, Ltd., Smederevo, Serbia \\ ${ }^{2}$ Key to Metals Ltd., Belgrade, Serbia \\ ${ }^{3}$ Telesign Ltd., Belgrade, Serbia, \\ ${ }^{4}$ Higher Court, Smederevo, Serbia
}

Received 11.08.2021

Accepted 12.12.2021

\begin{abstract}
This paper describes the computer model for BOF control that was in use at Smederevo, Serbia, during the period 1994-2006. The model was developed at the Institute of Metallurgy of the Smederevo Steelwork in mid-1994 and was motivated by the fact that the plant in Smederevo, by that time, had many years of experience in endpoint control using Intermediate Stop Practice (ISP). The vision for the model was to continuously improve and adapt to the working conditions of production through selflearning and adjustments. The model belongs to the well-known family of StaticDynamic models (SDMs). It is aimed to reduce the "oxygen off-to-start tap" time and thus increase productivity and reduce production costs. The paper briefly describes the metallurgical software, operator operations and provides some information on the model's effectiveness.
\end{abstract}

Keywords: BOF; Static-Dynamic model; quick tapping; cost; self-learning.

\section{Introduction}

Endpoint control in BOF steelmaking has a critical impact on the most important performance metrics of this widely used process in world steel production: cost, productivity, and quality. It considers all parameters to achieve the desired temperature, chemical composition, and weight of steel in the shortest possible time and at the lowest possible cost. The level of success in temperature and chemical composition control determines the tapping method (conventional, quick tap, or direct tap). It thus significantly affects the total duration of the heat (tap to tap). At the very beginning of the industrial application of the BOF process, endpoint control was supported by written

${ }^{*}$ Corresponding author: T. D. Bradarić, toma.bradaric@gmail.com 
instructions and the operator's experiences. After the advent of computers, this role was first taken over by static models and later by SDMs. This development was followed in parallel by improvements in methods for simultaneous temperature measurements, quick determination of the content of individual chemical elements, and metal sampling. Standard measurements today include measurements of temperature and carbon content (after about $90 \%$ of blown oxygen) and measurements of temperature and oxygen content (at the end of oxygen blowing). In both cases, metal samples are taken at the same time. These measurements are carried out manually with the turndown of converter (TD), or using sublances (SL) or in-blow drop sensors (IB) with the upright position of the converter. Many plants use chemical off-gas analysis mainly for endpoint carbon content control. Several descriptions of the BOF endpoint control testing methods can be seen in the papers [1-4]. According to the 2020 data from the largest association for iron and steel technology (AIST) [5], out of 71 BOF plants with a production capacity of around 260 million tons per year that are members of this association, only five shops use the turndown test exclusively. Of these five, three are with a capacity below 100t, and the remaining two use the Intermediate Stop Practice (ISP) method for endpoint control. According to this source, SL or IB methods are used in 47 plants (close to 70\%) and OG tests (off-gas analysis) in 37 plants. The SDM described in this paper is designed for ISP technology with the TD test, predefined metallic charge (hot metal and scrap), and does not include calculations for reblowing.

\section{Static-Dynamic Model - metallurgical software}

SDM consists of the following four groups of calculations that are performed successively on each of the three installed converters independently:

- calculations of the input materials and amount of oxygen (main blowing stage),

- calculation of the final blowing stage,

- estimation of metal chemistry at the end of blowing, and

- calculations intended for model adaptation (the corrective factors, correlation coefficients contained in the model).

Due to the cyclical way of production, all calculations are carried out alternately for three mutually adjacent heats: the heat in preparation, the heat in progress, and the just finished heat. All calculations are supported by a large number of data contained in the databases that follow:

- process parameters (parameters that change from time to time as total metallic charge, slag basicity, $\mathrm{MgO}$ content in slag, expected $\mathrm{P}, \mathrm{S}$ and Mn contents in hot metal, weight of flux),

- general data on non-metallic materials (physic-chemical characteristics of both types of lime, limestone, flux, FeSi as solid fuel),

- general data on product mix (steel grades with defined target parameters for the ends of both periods of oxygen blowing),

- database of completed heats intended for correction of coefficients in all relevant metallurgical relations - adaptation to the operating conditions of production, i.e. selflearning.

The entire process of calculations performed by the process operators is described as follows. 
Calculations of the input materials and amount of oxygen (main blowing stage)

Mathematical expressions for calculating all components of the heat and the amount of oxygen required were developed several years earlier [6] using dynamic modeling of all physical-chemical reactions during the converter process. This model was tested on four real heats at the Smederevo Steelwork, and, on that occasion, an excellent agreement between the actual values of the initial and final parameters of the process and the values obtained by the model was obtained. The charge calculation of the heat and the required amount of oxygen is performed in three steps. The flow chart of the calculation is shown in Figure 1

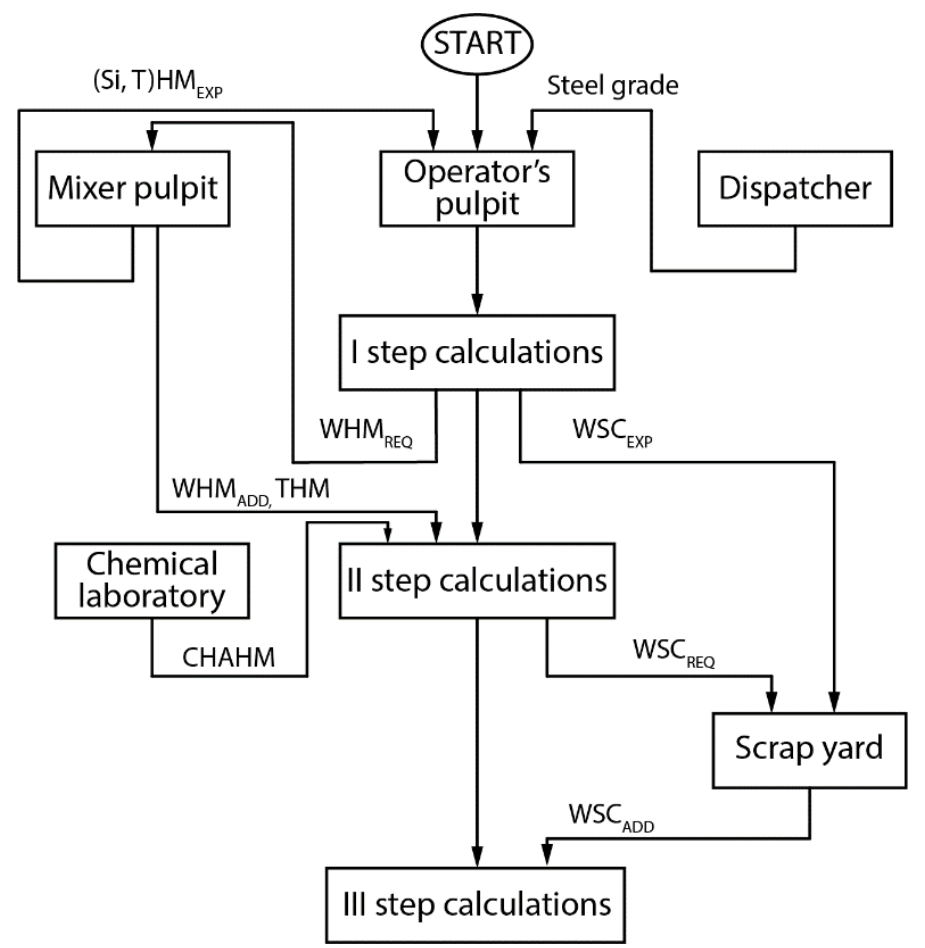

Fig. 1. Flow chart - calculations for the main blowing stage.

The purpose of the first and second steps is to calculate the optimal ratios of hot metal and scrap for a given total metallic charge limited by the maximum possible capacity of the converter. The first step is performed based on the expected values of the essential parameters of hot metal $\left((\mathrm{Si}, \mathrm{T}) \mathrm{HM}_{\mathrm{EXP}}\right)$, steel grade and the expected time from the end of the previous heat to the start of the next heat (manual input this data by an operator). The second step calculation is based on the actual values of all hot metal parameters $\left(\mathrm{WHM}_{\mathrm{ADD}}, \mathrm{THM}, \mathrm{CHAHM}\right)$. The second step of the calculation begins immediately after the automatic delivery of the chemical analysis, weight, and temperature of the hot metal, with the possibility of correcting the previously entered expected value of the delay time. In both of these calculation steps, operators obtain the values for corrective factors for heat balances and oxygen consumption (database of 
completed heats). The operators can also change the recommended value of the corrective factors for heat balances during the first step of calculations if they have a reason for it. The method for their calculation will be described in the fourth (last) group of calculations.

In the third step, based on the actual amount of scrap fed into the converter, the quantities of other components of the heat (both types of lime) and the amount of required oxygen are recalculated. These values are the final recommendations for process operators to implement. In cases when the weight of scrap ( $\mathrm{WSC}_{\mathrm{ADD}}$ ) differs from the one calculated in the second step, the following calculation results are shown: excess/lack of heat expressed in GJ, metal temperature that can be expected at the end of the first period of oxygen blowing due to scrap weight difference, as well as the recommended amount of cooling/heating materials to avoid temperature deviation. The operator is not obliged to implement this recommendation unless there is a significant deviation.

All above described calculations perform for predefined targets at the end of the first stage of oxygen blowing $(\mathrm{C}=0.22 \%, \mathrm{Fe}$ - tot $=11 \%)$, as and the slag basicity and $\mathrm{MgO}$ content in the final slag, located in the above mentioned databases. Only the target temperature is calculated based on the target temperature at the end of the second blowing period and its expected increase in the final blowing phase. This temperature increase is a variable that is continuously being updated based on the temperature increase on oxygen consumption in the second stage of blowing, when heating/cooling materials are not used (database of completed heats). The target value of carbon content at the end of the first blowing period of $0.22 \%$ was determined based on operational observation, which confirmed that the critical carbon content (content when the rate of carbon oxidation begins to decrease) was around $0.20-0.30 \%$ [7]. It was also experimentally found that, at this carbon content, the Fe_tot content in the slag is approximately $11 \%$ (converters without bottom stirring). The model assumes that slag contains twice as much iron oxide $(\mathrm{FeO})$ as oxide $(\mathrm{Fe} 2 \mathrm{O} 3)$.

\section{Calculation of the final blowing stage}

The dynamic part of the SDM is based on empirical changes in temperature and carbon content during the second period of oxygen blowing. In the model, for the constant intensity of oxygen blowing, such as in practice in Smederevo, it was assumed that the carbon content decreases exponentially and metal temperature increases linearly dependent on the amount of oxygen blown. This choice has been validated by the recent research conducted for small capacity converters such as the ones in use in Smederevo, where the constant updates to the coefficients based on mentioned dependencies led to adequate recommendations for process operators [8].

The calculation result in this phase of the process is the amount of oxygen that needs to be blown to reach the target values of carbon content and temperature at the end of blowing. If the calculation shows that there is a shortage/excess of heat, the amount of material for temperature trajectory corrections $\left(\mathrm{FeSi}\right.$ or $\left.\mathrm{CaCO}_{3}\right)$ is recommended. When recommending the addition of $\mathrm{FeSi}$, the amount of oxygen to be blown is adjusted for the part spent on silicon oxidation. For minor heat deficiencies, the calculation shows the lower carbon content (not less than $0.03 \%$ ) and the amount of oxygen the target temperature can be reached. The screen also shows operators the values of the correlation 
coefficients that describe how changes in temperature and carbon content were dependent on the amount of oxygen injected in the last 40 heats.

\section{Estimation of metal chemistry at the end of blowing}

The estimation of the carbon content is based on the measurement of oxygen activity at the end of oxygen blowing. Multiple linear regressions are used to estimate the content of other elements (Mn, P, and S). During this process, the values for Mn, P, and $\mathrm{S}$ from the control interruption of blowing, measured temperatures, and oxygen contents at the end of oxygen blowing, and the amount of oxygen blown are taken as independent variables. In parallel, the obtained differences between estimated and laboratory values for their contents are monitored. These differences are analyzed and used for periodic updates of the regression coefficients.

Calculation of the corrective factors, correlation coefficients contained in the SDM, and model adapting

The fourth group of calculations is also the last in the SDM, since the model in the first phase of its development did not include the calculation of recommendations in case of necessary additional oxygen blowing (reblowing). It starts by calculating the obtained deviations in the heat and oxygen consumption balances, which are used to correct both balances for the next heat (corrective factors). They are based on the obtained values at the last three heats, with their influence depending on the order of production and weighted at $10 \%, 30 \%$ and $60 \%$, with the last (most recent) heat being weighted the most.The remaining calculations include updates to all correlation coefficients intended to provide insight into the reliability of the assessments and recommendations contained in the SDM. They also serve, as well as the values above mentioned corrective factors, to indicate possible disturbances in the production process that need to be eliminated.

\section{SDM Implementation Results}

SDM testing began several months before the decision was made to start a project to increase the scrap ratio using solid fuels [9]. At that time, the SDM provided a more precise determination of the thermal effects of solid fuels used (such as fine coke, $75 \% \mathrm{FeSi}$, and waste $\mathrm{Al}$ ). Unfortunately, there are no complete data on the effects of the SDM during its implementation (mid-1994 - August 2002). Also, there is no data on how much the estimates of phosphorus and sulfur content at the end of blowing contributed to the increase in the share of quick tapping. Previously published works $[10,11]$ describe the share of OK heats and related trends for periods 1989 - 1995 (Figure 2) and 2002 March 2003 (Figure 3). The paper /10/ also contains the main metallurgical equipment of the BOF shop in Smederevo in that period. 


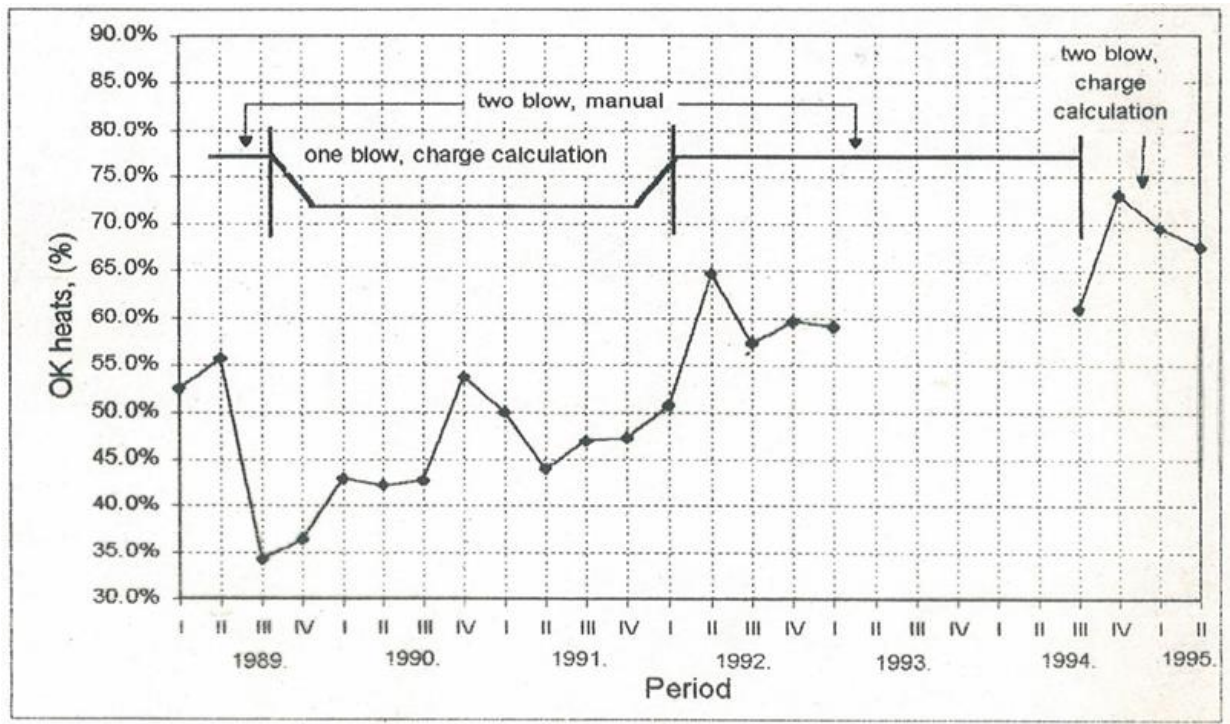

Fig.2. Quarterly turndown performance for the period 1898-1995 [10] (OK heat - heat without re-blow and with a temperature not higher than $15^{\circ} \mathrm{C}$ from the target).

Figure 2. shows the percentage of OK heats for three different endpoint control. Method "two blow, manual" represents the application of ISP (two blows), without the recommendations of static charge calculation models or tables and graphs. Method "one blow, charge calculation" represents the application of the static model and standard one period blowing practice. The third method (two blows, charge calculation) refers to the period of getting used to the domestic SDM, which is discussed in this paper. During this period, the static model of the consulting group that was hired at that time was used. During that period, hot metal was produced in electric-induction furnaces, and the production of slabs was performed every week with 7-8 heats in sequence (Mixer, 1300t capacity). This negatively affected the success of achieving OK heats.

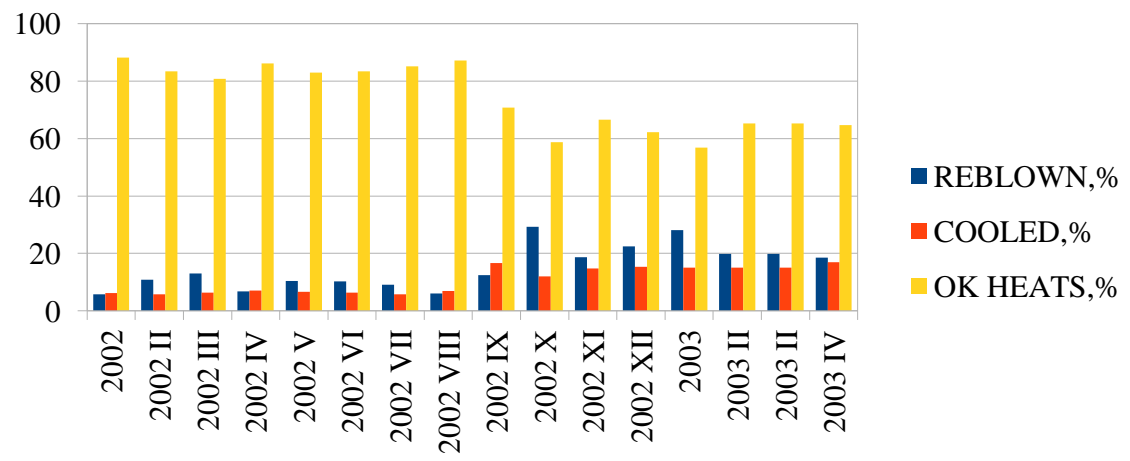

Fig. 3. Share of OK heats in the period 2002/2003 [11]. 
Figure 3. shows the success of achieving OK heats in the year when the new owner of Smederevo Steelwork, US Steel, decided to return to the "one blow" practice (SDM was in practice during the first eight months of 2002). The change was made due to the introduction of an unusual method to prolong the lining life of the converter, in which an approximately $0.8-1.2 \mathrm{t}$ mixture of $\mathrm{MgCO}_{3}$ and fine coke per heat in a ratio of about 9 to 1 is inserted into the converter at the very end of oxygen blowing. This SDM modified for "one blow" practice was used until the end of 2006, when the USS static model replaced it with new hardware support, which is still in use today.

Comparing the data shown in Figures 2 and 3, one can observe that the rate of OK heats increased from around 40-65\% when the ISP method ("two blows, manual") or static models were used, to about $85 \%$ when the SDM model was applied. A suitable example for the evaluation of this result can be the results reported in [12]. They were achieved in the BOF plant with a similar BOF control process that also did not have a device for reheating steel in the ladle. After a little more than a year since the transition from "one blow" to the ISP practice and with the use of the sublances (and for a similar definition of OK heats as in Smederevo), the rate of OK heats there increased from $39 \%$ to approximately $75 \%$.

\section{Conclusion}

Based on the above presented endpoint control performance at Smederevo Steelwork, it can be concluded that the SDM application led to significantly better results compared to the periods when the other two methods were used (ISP without static model or static model without ISP). The increase in the OK heats rate from about $40-65 \%$ to about $85 \%$ has certainly contributed to a significant reduction in the "oxygen off to start tap" time. In addition, the calculation results (instead of empirical estimates used before) for the $\mathrm{S}$ and $\mathrm{P}$ content at the end of blowing provided the opportunity to increase the quick tapping ratio. Both effects cause increased productivity, higher metallic yield, lower consumption of $\mathrm{Al}$ and refractory material, the ability to reduce temperatures at the end of blowing (an increase of scrap ratio), etc., thus reducing costs. A similar approach to improving the endpoint control (that includes mathematical modeling of the second phase of oxygen blowing, empirical testing, and development of the corresponding SDM) may be of interest for older BOF shops with smaller capacity converters and in particular for shops without devices for heating steel in ladles. An alternative could be the procurement of an SDM from companies that make it.

\section{Acknowledgment}

The first author T. Bradaric is grateful to Prof. Dr. Ljubomir Nedeljkovic for his mentorship and support during the preparation of his master thesis that was the basis for working on the SDM.

\section{References}

[1] P.D. Hubbeling, G.A. Oostermeijer, Sublance control. Sublance and dynamic control: The ultimate tool in steelmaking, AISE Annual Convention and Exposition 2003. http://digital.library.aist.org/pages/PR-337-063.htm; Accesed 11.2021.

[2] B.O. Chukwulebe, K. Robertson, J. Grattan, The Methods, Aims and Practices (MAP) for BOF Endpoint Control, AISTech 2007. 
[3] Subrat Mishra, Manish Wadhwa, Guido Van Hattum, Sublance: Ultimate Tool for Steelmaking, Technical report, 1/28/2016. http://www.meconlimited.co.in/writereaddata/MIST_2016/sesn/tech_4/4.pdf; Accesed 11.2021.

[4] Z. Wang, Q. Liu, H. Liu, S. Wei: High Temperature Materials and Processes, 39 (2020): 653-662.

[5] Association for Iron \& Steel Technology, PR-RU2021-8 - 2021 AIST Industry Roundups 2021 AIST Basic Oxygen Furnace Roundup168-177. http://digital.library.aist.org/pages/PR-RU2021-8.htm; Accesed 11.2021.

[6] T. Bradarić, Phenomenological dynamic model of steelmaking in LD converter, University of Belgrade, School for Technology and Metallurgy, Serbia, 1991, master thesis (in Serbian).

[7] V.I. Baptizmanskij, Oxygen-converter process theory, "Metallurgija", Moscow, 1975, 228/245 (in Russian).

[8] Z. Wang, Q. Liu, L. Cao, F. Xie, X. Lu, Research on the Model of Reblow Process for Small- and Middle-Capacity Converters, AISTech 2014.

[9] T.D. Bradarić, Z.M. Slović, K.T. Raić: Metallurgical and Materials Engineering 22 (2016): 101-106.

[10] T. Bradarić, Z. Slović, V. Simonović, R. Pilčević: Romanian society metallurgy, 4 (1996) 52-59.

[11] T. Bradarić, D. Stevanović, B. Vučinić, The first results of the changes in the BOF control in the USS BOF plant, VI Conference of Metallurgists of Serbia and Montenegro (synopsis collection), Arandjelovac, June 12-13, 2003, 80, (in Serbian).

[12] K.J. Robertson, S.R. Balajee, J.M. Shearer and J.E. Bradley, The Sublance Dynamic Control Operation and Its Effect on the Performance of the Inland Steel Company's No. 4 BOF Shop, I\&SM. August 1989, 36-42.

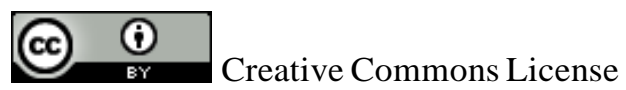

This work is licensed under a Creative Commons Attribution 4.0 International License. 